\title{
Determination of impurities in titanium nitride by slurry introduction axial viewed inductively coupled plasma optical emission spectrometry ${ }^{\text {th }}$
}

\author{
Zheng Wang ${ }^{\mathrm{a}, \mathrm{b}}$, Zheming $\mathrm{Ni}^{\mathrm{c}}$, Deren Qiu ${ }^{\mathrm{b}}$, Guangyi Tao ${ }^{\mathrm{a}}$, Pengyuan Yang ${ }^{\mathrm{b}, *}$ \\ ${ }^{a}$ Shanghai Institute of Ceramics, Graduate School of Chinese Academy of Sciences, Shanghai 200050, China \\ ${ }^{\mathrm{b}}$ Department of Chemistry, Fudan University, Shanghai 200433, China \\ ${ }^{\mathrm{c}}$ Research Center for Eco-Environmental Sciences, Academia Sinica, P.O. Box 2871, Beijing 100085, China
}

Received 26 August 2004; accepted 9 November 2004

\begin{abstract}
A method of slurry nebulization for inductively coupled plasma optical emission spectrometry (ICP-OES) applied to the analysis of titanium niride(TiN) was reported. The TiN slurry sample was prepared with adding dispersant polyacrylate amine or polyethylene imine for the stabilization and homogenization of suspension, and the amount of additives was optimized. A Babington type cross-flow nebulizer with V-groove was used for nebulization of the slurry for avoidance of blockage from the particles. The stability of slurry was characterized via zeta potential measurement, scanning electron microscope observation, particle size distrbution measurement and signal stability testing. For nm size TiN, calibration curves could be established by aqueous standards and the analytical results were in good accordance with the alkaline fusion method. For $\mu \mathrm{m}$ size TiN, a negative deviation was observed for most of elements and this deviation can be corrected by using Ti intrinsic internal standard method.
\end{abstract}

(C) 2005 Elsevier B.V. All rights reserved.

Keywords: Slurry; TiN; Axial ICP-OES; $\mathrm{NH}_{4} \mathrm{PAA}$; Intrinsic internal standard

\section{Introduction}

Titanium nitride (TiN) is currently a material of great technological importance because of its extreme hardness, abrasion resistance, high melting point, high chemical stability at elevated temperature, golden color and metallic conduction, and good thermal and electrical conductivity as well as superconductivity. TiN has many special uses ranging from reflectance and hardness coatings to microelectronic devices [1]. Recently the properties of $\mathrm{nm}$ titanium nitride particles reinforce with alumina or silicon

\footnotetext{
This paper was presented at the 6th European Furnace Symposium and 11th Solid Sampling Colloquium with Atomic Spectrometry, held in Balatonföldvár, Hungary, 27-30 June 2004, and is published in the special issue of Spectrochimica Acta Part B, dedicated to that conference.

* Corresponding author. Tel.: +86 21 65642009; fax: +86 2165642009 .

E-mail addresses: wangzheng@mail.sic.ac.cn (Z. Wang), pyyang@fudan.edu.cn (P. Yang).
}

nitride electro-conductive second phase to the matrix not only to improve some mechanical properties but also to lower drastically the electrical resistance [2]. However, its properties are significantly affected by some metal impurities. Determination of impurities in TiN powders is, therefore, of great importance.

TiN is an intractable refractory ceramic. Neutron activation analysis is probably a good method for the determination of impurities in solid TiN powder, but is not universally equipped in laboratories. X-ray spectroscopy is normally used to the analysis of solid sample, but needs solid standard samples with unsatisfactory limits of detection (LODs) for low-content determination requirements. Inductively coupled plasma optical emission spectrometry (ICP-OES) or inductively coupled plasma mass spectrometry (ICP-MS) normally requires transferring of the TiN powder into solution form. Even using modern strategies such as microwave-assisted acid digestion, TiN samples may still be hardly transferred into solution completely, in addition to a critical choice of acid 
mixture and amount and a heating program. An alternative is direct power analysis using slurry sample introduction with ICP-OES, which has been attracted increasing interests over the recent years [3-5]. In addition, axial viewing of the ICP has the potential of about 10 -fold improvement of LOD, which makes it more useful in micro and trace element determination [6,7]. It is an alternate for ICP-MS in a sense. Marjanovic et al. [8] and Silva et al. [9] used axial viewing ICP-OES for the analysis of slurries of cement samples and verified that slurry introduction could be used to axial ICP-OES only with some modification of the nebulizer and nebulization chamber.

Farinas et al. [10] mentioned that the two main factors determining the capability of the technique are the particle size of starting powders and the stability and homogeneity of slurry. In a comprehensive review of slurry nebulization Ebdon et al. [11] mentioned that only few in-depth studies in the references discussed the stabilizing effect of dispersants. It is also noticeable that the presented reports for the analysis of advanced materials using slurry technique for analytical atomic spectrometry were scarce of details of the characterization of slurry in order to reasonably prepare a stable suspension [12]. On the other hand, several authors reported that in case of slurry nebulization, transportation efficiency is strongly affected by the stability and homogeneity of aqueous slurries $[13,14]$.

Recently, the authors $[15,16]$ reported the determination of metal impurities in titanium dioxide and aluminum nitride using slurry sample introduction with axial viewing ICPOES and showed that preparation of a stable and homogeneous aqueous slurry is vital to the determination.

In this work, polyacrylate amine $\left(\mathrm{NH}_{4} \mathrm{PAA}\right)$ and polyethylene imine (PEI) were used as dispersant to stabilize and disperse the $\mu \mathrm{m}$ and $\mathrm{nm}$ particle size TiN. The stability and homogeneity of the suspensions were characterized with zeta potential measurement, scanning electron microscope (SEM) observation, particle size distribution measurement and signal stability testing. The prepared slurries were nebulized for axially viewed ICP-OES for determination of impurities in TiN. The results were presented and discussed.

\section{Experimental}

\subsection{Instrumentation}

All determinations were performed on a VISTA AX ICPOES spectrometer with axial view configuration (Varian, Australia). The sample introduction system consists of a Vgroove nebulizer and a reduced-volume Sturman-Masters Type spray chamber made of poly-tetrafluorethylene. Target integration time was set using the instrument software according to the intensity of analytical line to obtain the optimum signal-to-background ratio (SBR). The operating parameters and selected analytical lines are listed in Tables 1 and 2 , respectively.

\subsection{Materials and grinding method}

Two different sizes of TiN particle were selected for testing. The nm size TiN (Hefei Kiln Nanometer Technology Development) was utilized directly without grinding. The other is $\mu \mathrm{m}$ particle size (Northwest Institute for Nonferrous Metal Research). The material was grinded in the laboratory by a 'puck-type grinder' for $2 \mathrm{~min}$. The grinding container is made of tungsten carbide. The grinded sample was oven-dried at $110{ }^{\circ} \mathrm{C}$ for $2 \mathrm{~h}$.

\subsection{Preparation and characterization of slurries}

\subsubsection{Slurry preparation}

Slurry was prepared by weighing TiN sample then transferred into a $100 \mathrm{~mL}$ volumetric flask containing dispersant $\mathrm{NH}_{4} \mathrm{PAA}$ (Aldrich Chemical, USA) or PEI (BDH laboratory, UK). The $\mathrm{pH}$ was adjusted to a desired value with $\mathrm{HCl}$ or $\mathrm{NH}_{3}$ aqueous. Just before nebulization, the slurry was agitated in an ultrasonic bath for $15 \mathrm{~min}$ to ensure well dispersed and stable.

\subsubsection{Characterization of slurry}

2.3.2.1. Zeta potential measurement. Zeta potential of the prepared suspensions was measured with a Zeta-Plus Analyser (Brookhaven Instruments, USA). Suspensions were prepared by adding different amounts of dispersant in TiN powders, and then added water to make the TiN concentration as $0.01 \mathrm{vol} . \%$, including $0.001 \mathrm{~mol} / \mathrm{L} \mathrm{NaCl}$, to adjust ionic strength.

2.3.2.2. SEM observation. The suspensions were allowed to settle on a copper slice under gravity until a thin sediment film was formed. The sediment was then dried in the air and observed with a SEM (JSM-6700F, Japan). To detain high-

Table 1

Instrumentation and operating conditions

\begin{tabular}{ll}
\hline Spectral range & $167-785 \mathrm{~nm}$ \\
Viewing & Axial \\
RF generator & $40 \mathrm{MHz}$ \\
Torch & All-quartz \\
Injector tube diameter & $2.3 \mathrm{~mm}$ \\
Power & $1.25 \mathrm{~kW}$ \\
Plasma flow & $15 \mathrm{~L} / \mathrm{min}$ \\
Auxiliary flow & $1.5 \mathrm{~L} / \mathrm{min}$ \\
Nebulizer flow & $0.65 \mathrm{~L} / \mathrm{min}$ \\
Replicate read time & $3 \mathrm{~s}$ \\
Replicates & 3 \\
Instr. stabilization delay & $20 \mathrm{~s}$ \\
Sample uptake delay & $25 \mathrm{~s}$ \\
Rinse time & $10 \mathrm{~s}$ \\
Sample uptake rate & $0.8 \mathrm{~mL} / \mathrm{min}$ \\
\hline
\end{tabular}


Table 2

Selected analytical lines

\begin{tabular}{ll}
\hline Element & Spectral lines, $\mathrm{nm}$ \\
\hline $\mathrm{Ca}$ & 373.690 \\
$\mathrm{Cr}$ & 205.552 \\
$\mathrm{Fe}$ & 238.204 \\
$\mathrm{Mg}$ & 285.213 \\
$\mathrm{Ni}$ & 216.556 \\
$\mathrm{Si}$ & 288.158 \\
$\mathrm{Ti}$ & 334.188 \\
$\mathrm{Zr}$ & 327.305
\end{tabular}

quality micrographs, the sediments were coated with a thin gold layer prior to the measurement.

\subsubsection{Particle size determination. Particle size of $\mu \mathrm{m}$ TiN} was determined by a SICAS-4800 Photo-Sedimentometry (Shanghai Institute of Ceramics, CAS). Determination of particle size of $\mathrm{nm}$ TiN is on the basis of SEM image.

\subsection{Reagents and samples}

All reagents were of guarantee grade. The solutions were prepared with Mill-Q water $(18 \mathrm{M} \Omega \cdot \mathrm{cm})$. Calibration curves were established by using aqueous standards. The multielement working standards were prepared from 1000 $\mathrm{mg}^{-1}$ aqueous standards (Shanghai Institute of Measurement and Testing Technology, Shanghai, China). The blank and standards were prepared containing same amount of dispersant.

Series samples for standard additions were prepared as follows. Four samples of $0.1 \mathrm{~g}$ were weighed in $100 \mathrm{ml}$ Teflon beakers, suitable amounts of dispersant were individually added and three of the samples were spiked with linearly increments of a multi-element (Fe, $\mathrm{Mg}, \mathrm{Si}$, etc.) working standard solution. The first addition was approximately to the impurity contents, according to the semi-quantitative analysis.

A contrast sample was prepared by mixing the sample $(0.1 \mathrm{~g})$ with an alkaline flux $\left(2 \mathrm{~g}, \mathrm{Na}_{2} \mathrm{CO}_{3}+\right.$ borax $)$ and was fused in a Pt crucible for $30 \mathrm{~min}$. After cooling to room temperature, water was added to cover the fusion cake and was left overnight. The dissolved sample solution was transferred into a polyethylene volume flask and made up to volume of $100 \mathrm{ml}$ with water.

\section{Results and discussion}

\subsection{Particle size and size distribution}

Particle size distribution for $\mu \mathrm{m}$ size TiN and grinding effect was shown in Fig. 1. TiN has extreme hardness, abrasion resistance and is difficult to be milled. The original mean diameter of the $\mu \mathrm{m}$ particle size TiN powder is 7.5 $\mu \mathrm{m}$. After grinding, $80 \%$ particles of the TiN powder are less than $10 \mu \mathrm{m}$. The mean diameter is decreased to $4.9 \mu \mathrm{m}$, but still remains some large particles.

The SEM micrographs shown in Fig. 2 displayed the dispersion effect of adding dispersant $\mathrm{NH}_{4} \mathrm{PAA}$ or PEI in 2 wt.\% TiN suspension at pH 4. Large flocks were appeared in the suspension sediment with no dispersant, while particles of the sediments with dispersant were not high agglomerated, verifying that particles were well dispersed. This dispersion is beneficial to the stability of the slurry.

\subsection{Influence of $p H$ of the slurry on stability}

Surface of TiN particles has an electrical charge, depending upon the $\mathrm{pH}$ of the suspension medium due to the association of surface hydroxyl group with $\mathrm{H}^{+} / \mathrm{OH}^{-}$ ions, and a double electric layer is formed, the established potential is named as zeta potential. At a particular $\mathrm{pH}$ of suspension, the positive and negative activities will be equal and the overall potential at the particle surface will be zero. This $\mathrm{pH}$ is known as the isoelectric point (IEP) of the matter

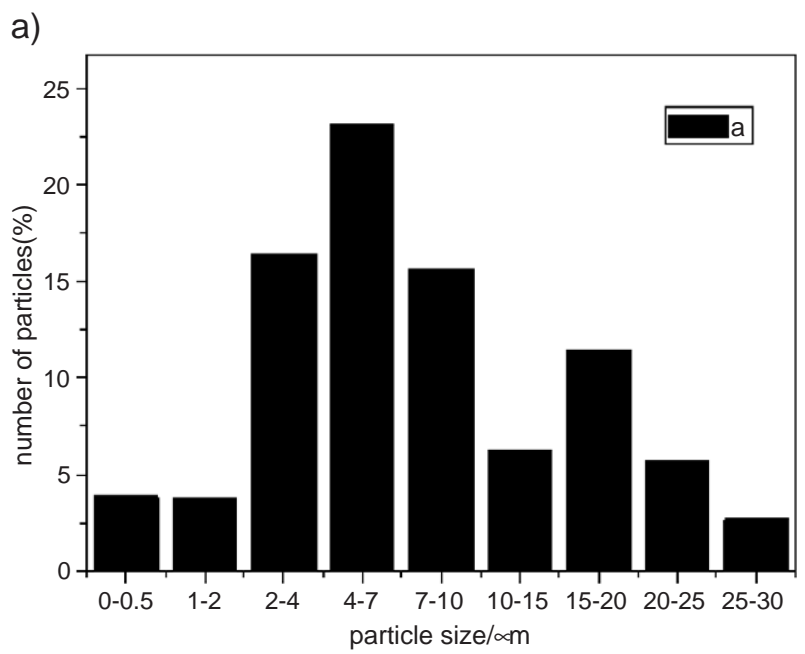

b)

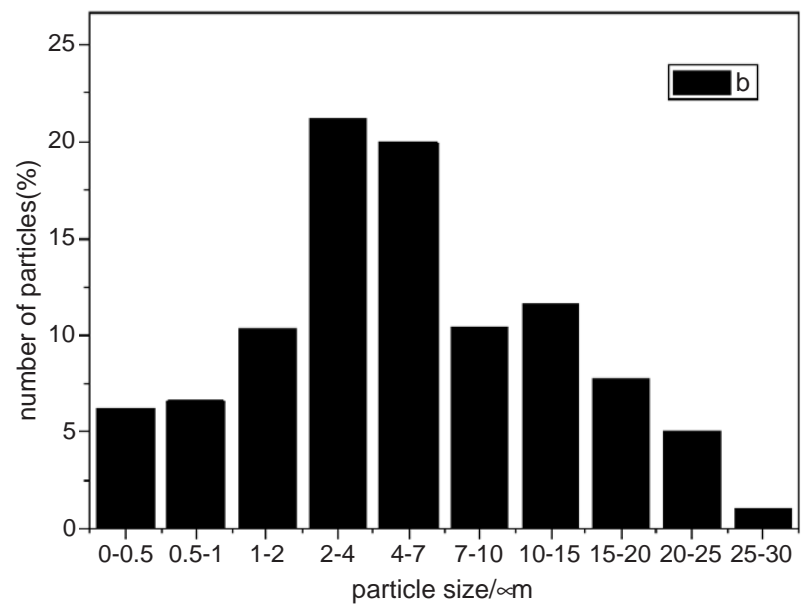

Fig. 1. Bar diagram for $\mu \mathrm{m}$ particle size power distribution determined by photosedimentometry, (a) original and (b) after grinding. 
(a)

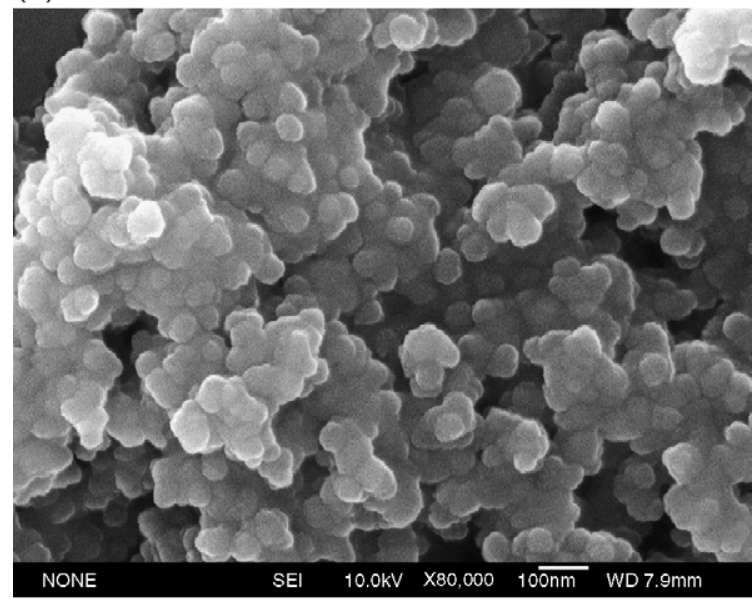

(b)

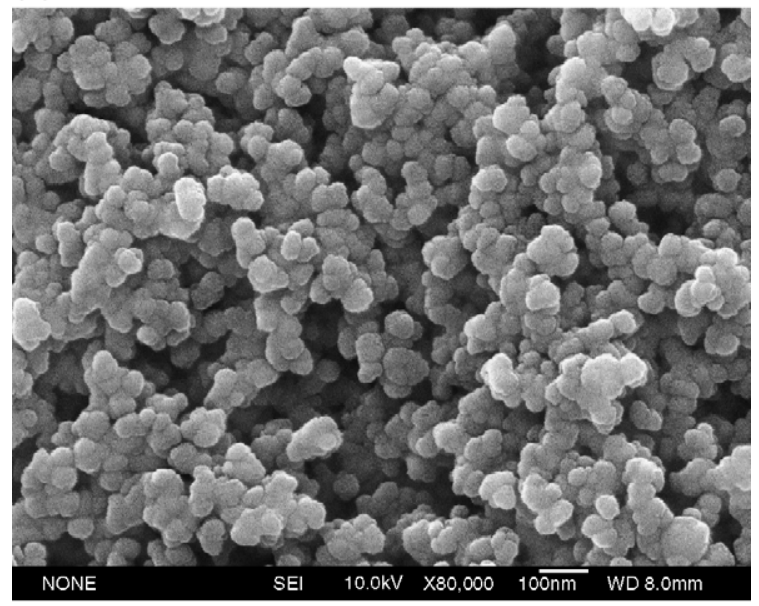

(c)

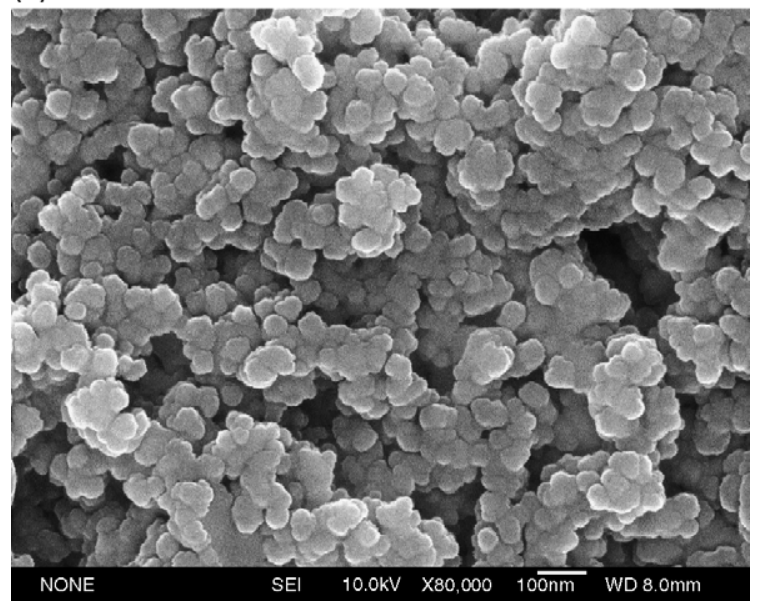

Fig. 2. SEM micrographs $(\times 80000)$ of sediments resulting from $2 \mathrm{wt} . \% \mathrm{~nm}$ TiN suspensions at $\mathrm{pH} 4.0$; (a) without dispersants, (b) with dispersants 1.0 wt. $\% \mathrm{NH}_{4} \mathrm{PAA}$, (c) with dispersants 2.0 wt.\% PEI.

and can be identified and expressed in terms of $\mathrm{pH}$ value. Farinas et al. [10] and Ebdon et al. [11] have described the fundamentals in details. At IEP, slurry will be unstable and the particles will be agglomerated. The slurry is stable only in case that the zeta potential is far away from the IEP. In other words, stability of the slurry can be described in terms of zeta potential measurement.

Figs. 3-5 show the relationships of the zeta potential vs. $\mathrm{pH}$ for $\mathrm{nm}$ size TiN with dispersant $\mathrm{NH}_{4} \mathrm{PAA}, \mathrm{nm}$ size TiN with dispersant PEI and $\mu \mathrm{m}$ size TiN with $\mathrm{NH}_{4} \mathrm{PAA}$, respectively. All of them show that the zeta potential is considerably varied with $\mathrm{pH}$. The IEP of both the native $\mathrm{nm}$ particle size and the $\mu \mathrm{m}$ particle size TiN are approximately at $\mathrm{pH} 4.0$, similar to the value reported by $\mathrm{Li}$ [17]. According to the Figs. 3-5, the stability can be achieved at basic $\mathrm{pH}$ values, as the zeta potential is far away from the IEP in this $\mathrm{pH}$ zone. However, the viscosity becomes very high in basic range and a great difference in nebulization will be occurred compared to the aqueous standards [10].

\subsection{Effect of dispersant and dispersant amount on slurry stability}

Effects of different dispersant and dispersant amount on slurry stability were also shown in Figs. 3-5. The absorbed polyelectrolytes create a large energy barrier of preventing the colloid particles from flocculation. Due to the differences in surface properties, as a rule, it is necessary to use a certain dispersing agent for individual powder.

It can be seen in Fig. 3 that the IEP shifts with the addition of $\mathrm{NH}_{4} \mathrm{PAA}$ and that the zeta potential becomes more negative and the IEP shifts toward acidic region. In range of $\mathrm{pH} 4-10$ the zeta potentials kept constant $(-60$ $\mathrm{mV}$ ). Fig. 4 shows that the IEP shifts with the PEI addition to the basic zone. However, the concentration of the dispersant should also be controlled; too much excessive dispersant would destroy the stability of slurry and causes an increase of viscosity [10]. Figs. 3-5 show that amount of 1.0 wt. $\% \mathrm{NH}_{4} \mathrm{PAA}, 2.0$ wt. $\%$ PEI, 0.8 wt. $\% \mathrm{NH}_{4} \mathrm{PAA}$ may be suitable for dispersing the nm TiN and $\mu \mathrm{m}$ TiN powder, separately. The zeta potential was essentially much more than $40 \mathrm{mV}$ in range of $\mathrm{pH} 2-8$ for $\mathrm{NH}_{4} \mathrm{PAA}$ (Fig. 3).

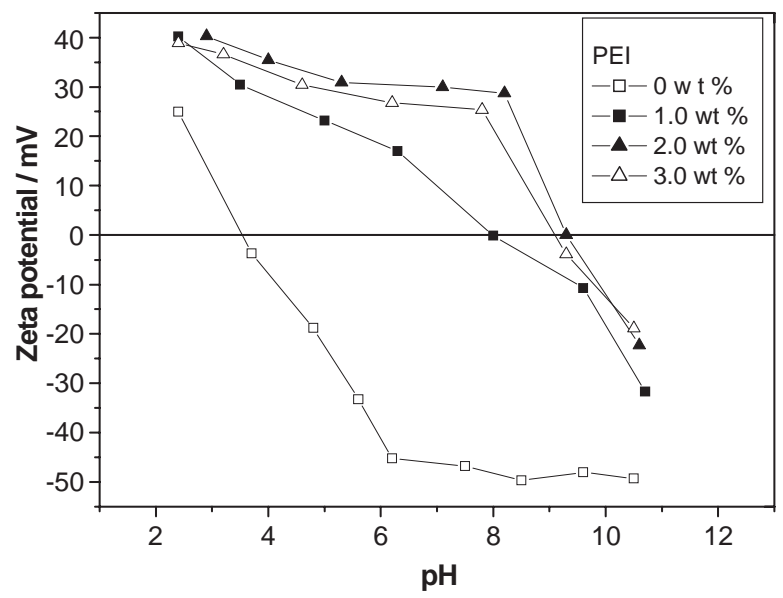

Fig. 3. Profiles of zeta potential vs. $\mathrm{pH}$ for $\mathrm{nm}$ particle size TiN slurry at different $\mathrm{NH}_{4}$ PAA concentrations. ( $\square, 0$ wt.\%; 0.5 wt. $\%$; $\boldsymbol{\Delta}, 1.0$ wt.\%; $\triangle, 2.0$ wt. $\%$ ). 


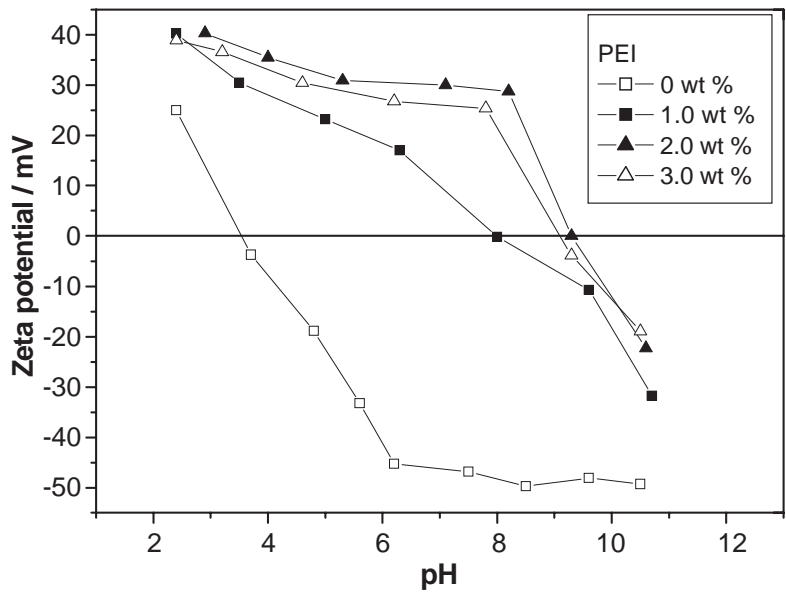

Fig. 4. Profiles of zeta potential vs. $\mathrm{pH}$ for $\mathrm{nm}$ particle size TiN slurry at different PEI concentrations. ( $\square, 0$ wt. $\% ; \boldsymbol{\square}, 1.0$ wt. $\% ; \boldsymbol{\Delta}, 2.0$ wt. $\% ; \Delta$, 3.0 wt. $\%$ )

However, the zeta potential was $30 \mathrm{mV}$ for PEI (Fig. 4). It means that $\mathrm{NH}_{4} \mathrm{PAA}$ has a better dispersion and stability effect than PEI.

\subsection{Relationship of signal intensity and slurry stability}

Slurry stability was experimentally tested as shown in Fig. 6. The nm size TiN slurry, as a representative, displays unstable performance with no dispersant at IEP, the normalized intensities of matrix $\mathrm{Ti}$ and impurities $\mathrm{Fe}, \mathrm{Si}$ are obviously decreased with time (Fig. 6(a)). Comparatively, the slurry with $\mathrm{NH}_{4} \mathrm{PAA}$ (1.0 wt.\%) (Fig. 6 (b)) or dispersant PEI (2.0 wt.\%) (Fig. 6(c)), zeta potential is far from IEP, displays the stable spectroscopic intensities. Meanwhile, $\mathrm{NH}_{4} \mathrm{PAA}$ plays a better role of stabilization than PEI. The Ti intensity of start point (nearly $0 \mathrm{~min}$ ) was also determined. It agrees well with the SEM observation.

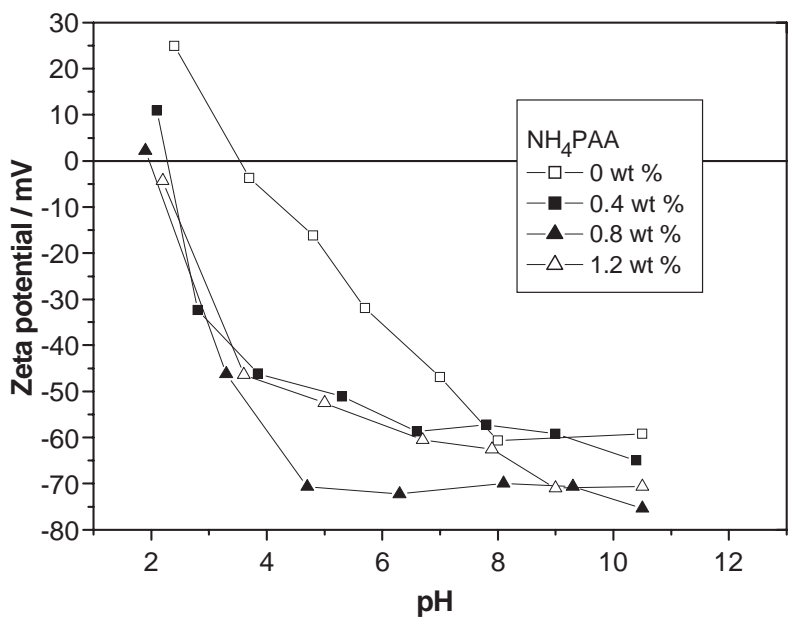

Fig. 5. Profiles of zeta potential vs. $\mathrm{pH}$ for $\mu \mathrm{m}$ particle size TiN slurry at different $\mathrm{NH}_{4}$ PAA concentrations. ( $\square, 0$ wt.\%; $\mathbf{\square}, 0.4$ wt. \%; $\boldsymbol{\Delta}, 0.8$ wt.\%; $\Delta, 1.2$ wt. $\%$ ).

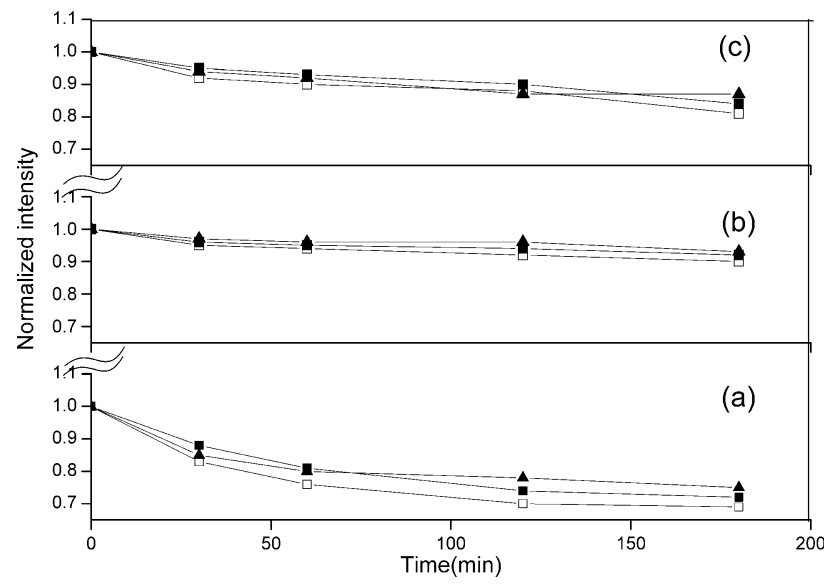

Fig. 6. Profiles of normalized intensity vs. time for nm particle size TiN slurry at $\mathrm{pH} 4.0$; (a) without dispersant, (b) with dispersant $1.0 \mathrm{wt} \%$ $\mathrm{NH}_{4}$ PAA, (c) with dispersant 2.0 wt.\% PEI. ( $\square$, Ti; $\boldsymbol{\square}, \mathrm{Fe} ; \boldsymbol{\Delta}, \mathrm{Si}$ ).

\subsection{Calibration technique and analytical results}

The analytical results for $\mathrm{nm}$ size and $\mu \mathrm{m}$ size of $\mathrm{TiN}$ are listed in Tables 3 and 4, respectively. It can be seen in Table 3 that for nm size TiN, calibration using aqueous standards, slurry nebulization method gives identical results with the fusion prepared sample, also with the standard additions method. Even for matrix $\mathrm{Ti}$, the determined percentage content $64.54 \pm 1.24$ agrees with the chemical titration percentage result $63.52 \pm 0.21$, using a same aqueous $\mathrm{Ti}$ standard. This means that efficiency of transportation and atomisation of the $\mathrm{nm}$ particles of $\mathrm{TiN}$ is substantially identical to the aerosol of the aqueous standards. In other words, aqueous standards can be used to create calibration curves for the slurry nebulization ICP-OES analysis of nm size TiN.

It is quite another thing for $\mu \mathrm{m}$ particle size TiN. As can be seen in Table 4, all the analytical results ( 2 nd column) are obviously deviated on the low side, compared to the results of fusion prepared same sample (3rd column). Additionally, method of standard additions has been tested and proved of still no avail to the correction. Similarly, addition of indium as an internal standard to the slurry has also reasonably been proved no effect for correction. The most rigorous studies reported that slurry particles large than $5 \mu \mathrm{m}$ (in some

Table 3

Analytical results for $\mathrm{nm}$ particle size of TiN $(n=5)$

\begin{tabular}{lccc}
\hline Element & $\begin{array}{l}\text { Slurry } \\
\text { introduction } \\
(\mu \mathrm{g} / \mathrm{g})\end{array}$ & $\begin{array}{l}\text { Alkaline } \\
\text { fusion } \\
(\mu \mathrm{g} / \mathrm{g})\end{array}$ & $\begin{array}{l}\text { Standard } \\
\text { additions } \\
\text { method }(\mu \mathrm{g} / \mathrm{g})\end{array}$ \\
\hline $\mathrm{Ca}$ & $64 \pm 5$ & - & $71 \pm 6$ \\
$\mathrm{Cr}$ & $22 \pm 2$ & $25 \pm 3$ & $24 \pm 3$ \\
$\mathrm{Fe}$ & $138 \pm 20$ & $146 \pm 22$ & $141 \pm 18$ \\
$\mathrm{Mg}$ & $6 \pm 2$ & - & - \\
$\mathrm{Ni}$ & $10 \pm 4$ & $10 \pm 3$ & - \\
$\mathrm{Si}$ & $341 \pm 25$ & $327 \pm 21$ & $335 \pm 17$ \\
$\mathrm{Zr}$ & $7 \pm 1$ & $6 \pm 3$ & - \\
$\mathrm{Ti}$ & $64.54 \pm 1.24$ & $63.97 \pm 1.84$ & - \\
\hline
\end{tabular}


Table 4

Analytical results for $\mu \mathrm{m}$ particle size of TiN $(n=5)$

\begin{tabular}{lccc}
\hline Element & $\begin{array}{l}\text { Slurry } \\
\text { introduction } \\
(\mu \mathrm{g} / \mathrm{g})\end{array}$ & $\begin{array}{l}\text { Alkaline } \\
\text { fusion } \\
(\mu \mathrm{g} / \mathrm{g})\end{array}$ & $\begin{array}{l}\text { Result using } \\
\text { an intrinsic } \\
\text { internal standard } \\
\text { correction }(\mu \mathrm{g} / \mathrm{g})\end{array}$ \\
\hline $\mathrm{Ca}$ & $14 \pm 1$ & - & $62 \pm 4$ \\
$\mathrm{Cr}$ & $17 \pm 2$ & $80 \pm 10$ & $76 \pm 9$ \\
$\mathrm{Fe}$ & $134 \pm 11$ & $604 \pm 26$ & $598 \pm 49$ \\
$\mathrm{Mg}$ & $70 \pm 2$ & $318 \pm 19$ & $303 \pm 9$ \\
$\mathrm{Ni}$ & $5 \pm 1$ & $26 \pm 3$ & $22 \pm 4$ \\
$\mathrm{~Pb}$ & $3.1 \pm 0.7$ & $15 \pm 3$ & $18 \pm 3$ \\
$\mathrm{Si}$ & $71 \pm 5$ & $320 \pm 14$ & $317 \pm 22$ \\
$\mathrm{Zr}$ & $24 \pm 1$ & $116 \pm 5$ & $107 \pm 4$ \\
$\mathrm{Ti}$ & $14.26 \pm 0.42$ & $63.70 \pm 1.76$ & - \\
\hline
\end{tabular}

studies $2 \mu \mathrm{m}$ ) do not reach the plasma and result in a loss of signal [11]. Aerosol behavior of transportation and atomization in central channel of the ICP torch has been thoroughly studied. However, slurry particles has a quite different behavior from aerosol, evaporation of the particles may be the bottleneck. Raeymaekers et al. [18] and Van Borm et al. [19] studied influence of particle size of $\mathrm{Al}_{2} \mathrm{O}_{3}$ and $\mathrm{SiO}_{2}$ on transportation and atomization efficiencies. In this work, deviation of the results for $\mu \mathrm{m}$ particle size TiN can be predominantly attributed to the incomplete evaporation of the $\mu \mathrm{m}$ particle size TiN (high melting point 2930 ${ }^{\circ} \mathrm{C}$ ) and also to the different transportation efficiency between $\mu \mathrm{m}$ particle size TiN suspension and aqueous solution [20].

Intrinsic internal standard [11] is a promising approach to the correction of deviation resulting in incomplete evaporation and atomization. Considering $\mathrm{Ti}$ in TiN is existed in a constant content, it is reasonably appropriate to select $\mathrm{Ti}$ as the intrinsic internal standard for the correction. The matrix Ti was determined and correction coefficient for all courses of transportation, evaporation and atomization during the slurry stay in the experimental system can be determined via calculating of the spectrometric data (content) and the chemical titration data (content), which was taken from chemically complete dissolution of TiN. A correction coefficient can thus be calculated as 4.47 . The coefficient was then applied to the correction of results of slurry method. Final results after intrinsic internal standard correction were listed in Table 4 (last column). The results using intrinsic internal standard correction were in good accordance with that by an alkaline fusion method. It is not too much to say that the slurry procedure with an intrinsic internal standard correction for $\mu \mathrm{m}$ particle size TiN is at least acceptable as a semi-quantitative method for the rapid screening analysis.

\section{Conclusions}

The dispersing effect of $\mathrm{NH}_{4} \mathrm{PAA}$ and PEI for $\mathrm{nm}$ and $\mu \mathrm{m}$ particle size TiN suspensions and slurry nebulization for
ICP-OES determination has been investigated. Stability of the suspension was characterized with the zeta potential measurement, SEM observation, particle size distribution measurement and signal stability testing. Characterization shows that both $\mathrm{NH}_{4} \mathrm{PAA}$ and $\mathrm{PEI}$ are the good dispersant for preparation of TiN suspension. However, $\mathrm{NH}_{4} \mathrm{PAA}$ is superior to PEI in performance of dispersion. The $\mathrm{nm}$ particle size TiN can be analyzed using slurry nebulization ICP-OES with aqueous standards calibration, and analysis of $\mu \mathrm{m}$ size TiN should be carried out by using intrinsic internal standard method considering the matrix $\mathrm{Ti}$ as the intrinsic internal standard.

\section{Acknowledgements}

The authors are grateful to Shanghai Committee of Science and Technology (0159nm075) and Shanghai Institute of Ceramics, CAS (ZRJJ 200401) for financial support.

\section{References}

[1] J. Hu, Q. Lu, K. Tang, S. Yu, Y. Qian, G. Zhou, X. Liu, Lowtemperature synthesis of nanocrystalline titanium nitride via a benzene-thermal route, J. Am. Ceram. Soc. 83 (2000) 430-432.

[2] J. Li, L. Gao, J. Guo, D. Yan, Novel method to prepare electroconductive titanium nitride-aluminum oxide nanocomposites, J. Am. Ceram. Soc. 85 (2002) 724-726.

[3] T. Graule, A.V. Bohlen, J.A.C. Broekaert, E. Grallath, R. Kloekenkamper, P. Tsehopel, G. Tolg, Atomic emission and atomic absorption spectrometric analysis of high-purity powders for the production of ceramics, Fresenius' J. Anal. Chem. 335 (1989) $637-642$.

[4] B. Docekal, J.A.C. Broekaert, T. Graule, P. Tsehopel, G. Tolg, Determination of impurities in silicon carbide powders, Fresenius' J. Anal. Chem. 342 (1992) 113-117.

[5] J.A.C. Broekaert, C. Lathen, R. Brandt, C. Pilger, P. Pollmann, P. Tsehopel, G. Tolg, The use of plasma atomic spectrometric methods or the analysis of ceramic powders, Fresenius' J. Anal. Chem. 349 (1994) 20-25.

[6] I.B. Brenner, A.T. Zander, Axially and radially viewed inductively coupled plasmas - a critical review, Spectrochim. Acta Part B 55 (2000) 1195-1240.

[7] F.V. Silva, L.C. Trevizan, C.S. Silva, A.A. Nogueira, J.A. Nobrega, Evalution of inductively coupled plasma optical emission spectrometers with axially and radially viewed configurations, Spectrochim. Acta Part B 57 (2002) 1905-1913.

[8] L. Marjanovic, R.I. Mccrindle, B.M. Botha, J.H. Potgieter, Analysis of cement by inductively coupled plasma optical emission spectrometry using slurry nebulization, J. Anal. At. Spectrom. 15 (2000) 983-985.

[9] S. Silva, T. Blanco, J.A. Nobrega, Analysis of cement slurries by inductively coupled plasma optical emission spectrometry with axial viewing, Spectrochim. Acta Part B 57 (2002) 29-33.

[10] J.C. Farinas, R. Moreo, J.M. Mermet, Effect of colloidal stability of ceramic suspensions on nebulization of slurries for inductively coupled plasma atomic emission spectrometry, J. Anal. At. Spectrom. 9 (1994) 841-849.

[11] L. Ebdon, M. Foulkes, K. Sutton, Slurry nebulization in plasma, J. Anal. At. Spectrom. 12 (1997) 213-229. 
[12] A. Fisher, M.W. Hinds, S.N. Nelms, D.M. Penny, P. Goodall, Atomic spectrometry update.industrial analysis: metals, chemicals and advanced materials, J. Anal. At. Spectrom. 17 (2002) 1624-1649.

[13] I. Varga, F. Csempesz, G. Zaray, Effect of $\mathrm{pH}$ of aqueous ceramic suspensions on colloidal stability and precision of analytical measurements using slurry nebulization inductively coupled plasma atomic emission spectrometry, Spectrochim. Acta Part B 51 (1996) $253-259$

[14] Z. Wang, Z. Ni, D. Qiu, T. Chen, G. Tao, P. Yang, Winter Conference on Plasma Spectrochemistry, Fort Lauderdale, Florida, TP13, 2004.

[15] Z. Wang, Z. Ni, D. Qiu, T. Chen, G. Tao, P. Yang, Determination of metal impurities in titanium dioxide using slurry sample introduction by axial viewing inductively coupled plasma optical emission spectrometry, J. Anal. At. Spectrom. 19 (2004) 273-276.

[16] Z. Wang, Z. Ni, D. Qiu, G. Tao, P. Yang, Royal Society of Chemisty Analytical Division Atomic Spectroscopy Group, 12th BNASS 2004, University of Plymouth, UK, TP14, 2004.
[17] J. Li, L. Gao, J. Guo, Effect of PAA-NH $\mathrm{NH}_{4}$ on properties of aqueous nano TIN suspensions, J. Mater. Sci. Lett. 21 (2002) 509-511.

[18] B. Raeymaekers, T. Graule, J.A.C. Broekaert, F. Adams, P. Tsehopel, Characteristics of nebulized suspensions of refractory oxidepowders used for the production of ceramics and their evaporation behavior in used for the production of ceramics and their evaporation behaviour in an inductively coupled plasma, Spectrochim. Acta Part B 43 (1988) $923-940$

[19] W.A.H. Van Borm, J.A.C. Broekaert, R. Kloekenkamper, Aerol sizing and transport studies with slurry nebulization in inductively coupled plasma spectrometry, Spectrochim. Acta Part B 46 (1991) $1033-1049$

[20] L. Ebdon, M. Foulkes, S. Hill, Direct atomic spectrometric analysis by slurry atomisation part 9 . Fundamental studies of refractory samples, J. Anal. At. Spectrom. 5 (1990) 67-73. 